\title{
A DIMENSÃO ÉTICA DO AGIR E AS QUESTÕES DA QUALIDADE COLOCADAS FACE AOS CUIDADOS DE ENFERMAGEM ${ }^{1}$
}

\author{
Goreti Mendes²
}

\begin{abstract}
${ }^{1}$ Este trabalho foi realizado no âmbito do Curso de Doutoramento em Enfermagem da Universidade Católica Portuguesa.
${ }^{2}$ Doutoranda em Enfermagem da Universidade Católica Portuguesa. Professora Coordenadora da Escola Superior de Enfermagem da Universidade do Minho. Braga, Portugal. E-mail: gmendes@ese.uminho.pt
\end{abstract}

RESUMO: Neste artigo procuramos reflectir sobre a dimensão ética do agir em enfermagem e a qualidade dos cuidados de saúde prestados. São analisados os princípios predominantemente colocados à reflexão, os quais pretendem ajudar na tomada de decisões cada vez mais complexas. Destacamos a ética do cuidado, cuja perspectiva tem especial significado nas relações que se estabelece. Falar sobre a dimensão ética do agir, quando a desumanização dos contextos e das relações profissionais se tornou uma preocupação crescente, leva a que se questione a qualidade dos cuidados de enfermagem. Estes cuidados desenvolvidos com base no respeito pela vida, dignidade e direitos humanos, devem constituir-se na garantia da defesa da liberdade da pessoa humana. Só nesta perspectiva, faz sentido evocar a qualidade da assistência à saúde. A dimensão ética assume particular relevância no processo de tomada de decisão e a sua clarificação e assunção por parte dos enfermeiros, nos seus comportamentos profissionais, torna-se um imperativo.

DESCRITORES: Ética. Cuidados de enfermagem. Qualidade da assistência à saúde

\section{THE ETHICAL DIMENSION OF ACTION AND THE QUESTIONS OF QUALITY FACING NURSING CARE}

\begin{abstract}
In this article we seek to reflect on the ethical dimension of nursing action and the quality of health care provided. We analysed the predominant principles exposed to reflection, aiming to improve ever more complex decision-making processes. We highlight the ethics of care, whose perspective reflects a special meaning in the relationships it establishes. To talk about the ethical dimension of action, when the dehumanization of contexts and professional relationships has already become a growing source of concern, leads one to enquire about the quality of nursing care. These instances of care developed on the basis of the respect for the, dignity, and human rights, should be considered a guarantee of the defence of human freedoms. Only in such a perspective does it make sense to evoke the quality of health care. The ethical dimension assumes particular relevance in the health care decision-making process and its clarification and assumption by nurses, in their professional behaviour, becomes imperative.
\end{abstract}

DESCRIPTORS: Ethics. Nursing care. Quality of health care.

\section{LA DIMENSIÓN ÉTICA DE LA ACCIÓN Y LAS CUESTIONES RELATIVAS A LA CALIDAD DE LOS CUIDADOS DE ENFERMERIA}

RESUMEN: En este artículo se pretende reflexionar sobre la dimensión ética de la acción de enfermaría y la calidad de los cuidados de salud prestados. Se analizaron los principios fundamentales expuestos en la reflexión, con el objetivo de ayudar en la toma de decisiones cada vez más complejas. Se destaca la ética del cuidado, cuya perspectiva tiene especial significado en las relaciones que se establecen. Hablar acerca de la dimensión ética de la acción, cuando la deshumanización de los contextos y de las relaciones profesionales ya se han convertido en una fuente creciente de preocupación, conduce al cuestionamiento de la calidad de los cuidados de enfermaría. Esos cuidados desarrollados sobre la base del respecto a la vida, la dignidad y los derechos humanos, deben constituirse en garantía de defensa de la libertad del ser humano. Sólo desde esa perspectiva tiene sentido considerar la calidad de la atención a la salud. La dimensión ética adquiere una especial relevancia en el proceso de toma de decisiones y su clarificación y asunción por parte de los enfermeros en su comportamiento profesional, se convierte en un imperativo.

DESCRIPTORES: Ética. Cuidados de enfermaría. Calidad de la atención de salud. 


\section{INTRODUÇÃO}

A dimensão ética do agir e a qualidade dos cuidados de enfermagem que são prestados são a questão central desta reflexão que, a par de outras, surgiu na sequência da leitura de um artigo relacionado com a ética do cuidado. ${ }^{1}$ Alguns questionamentos também foram emergindo da reflexão referente à conduta dos enfermeiros e ao seu valor moral, à essência dos cuidados de enfermagem, à experiência humana na relação, ao conhecimento e às formas de ser e de estar.

A ética do cuidado remete-nos para as teorias baseadas nas relações, cuja perspectiva assume especial significado no desempenho de papéis sociais. A relação e o compromisso existentes exigem uma resposta que inclua sentimentos de compaixão e confiança e a garantia de uma relação especial que reconheça o outro como pessoa singular. ${ }^{2}$

Falar de ética em enfermagem leva a que necessariamente se considere os cuidados específicos da sua actividade, os quais faz sentido evocar a partir de uma perspectiva orientada para o seu desenvolvimento. ${ }^{1}$

A franca evolução das sociedades e a procura constante do equilíbrio entre o bem individual e o bem colectivo têm demonstrado, de uma forma clara, que a ética constitui-se num pilar fundamental. Ela assume, cada vez mais, a centralidade das decisões nas quais os enfermeiros se vêem envolvidos. E enquanto agentes sociais que são devem-se comprometer com a garantia de uma prestação de cuidados de qualidade aos cidadãos.

"O enfermeiro é o profissional a quem foi atribuído um título profissional que lhe reconhece competência científica, técnica e humana para a prestação de cuidados de enfermagem gerais ao indivíduo, família grupos ou comunidades

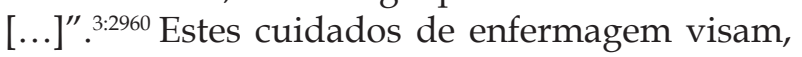
prioritariamente, a ajuda na adaptação aos processos de vida e às situações de saúde/doença experienciadas pela pessoa, enquanto alvo de cuidados, e complementam também a actuação de outros profissionais na resolução dos problemas de saúde que a acomete.

"Pensamos espontaneamente que não há, com efeito, ética de enfermagem sem cuidados de qualidade" ${ }^{1: 5}$ E percebemos que os cuidados de enfermagem não se limitam a exigir a competência técnica mas que esta deve ser atravessada pelo sentido do humano. Isso leva-nos a questionar, como é que o enfermeiro se concretiza enquanto enfermeiro nos cuidados que vai desenvolvendo?
Esta reflexão pretende constituir-se num contributo para os enfermeiros que assumem uma capacidade crescente para pautar novas formas de Ser e Estar face aos cuidados que prestam.

\section{PARTILHANDO A REFLEXÃO...}

Se pensarmos que prestar cuidados de enfermagem, enquanto actividade profissional, implica sempre lidar com uma escala de valores, seus e dos outros e que os mesmos são a referência para a forma de estar e viver, na relação com o mundo e com os outros, mais facilmente podemos compreender a importância cada vez maior, que a decisão ética ocupa no processo de cuidados. ${ }^{4}$

Falar de cuidados de enfermagem, os quais têm por fundamento uma interacção, uma relação de ajuda com o outro, leva a que se considere também as intervenções, as quais são "[...]realizadas com a preocupação da defesa da liberdade e da dignidade da pessoa humana e do enfermeiro". Sendo realizadas com a preocupação máxima do respeito pelo outro, podem tender para a excelência.

Também no Regulamento do Exercício Profissional do Enfermeiro em Portugal, vemos explicitado que "no exercício das suas funções, os enfermeiros deverão adoptar uma conduta responsável e ética e actuar no respeito pelos direitos e interesses legalmente protegidos dos cidadãos" .6:2961

Nos diversos contextos de operacionalização de cuidados, onde a desumanização das relações profissionais se tornou uma preocupação crescente, uma ética baseada no cuidado e na preocupação pelos outros, pode ser um grande contributo para a ética na saúde em geral. A ética do cuidado apregoa que são as relações humanas estabelecidas que permitem defender as pessoas vulneráveis, dependentes, doentes e frágeis, bem como satisfazer as suas necessidades. ${ }^{7}$

O ser humano é um ser ético. Cada homem e cada mulher têm a responsabilidade de si mesmo. Ser responsável, é poder responder a desafios, a chamadas, a tarefas imprevistas que se propõem no caminho de vida de cada um. A ética interfere também na capacidade de saber dizer não a determinadas pulsões do corpo ou da mente, para ordenar os nossos actos na linha de uma verdadeira finalidade ética. ${ }^{8}$ No desenvolvimento das nossas relações interpessoais deve respeitar-se a pessoa pelo "simples facto de o ser". Também na prestação dos cuidados, o enfermeiro não deve ser influenciado por qualquer consideração de nacionalidade, de ordem política ou social, raça, crença, cor, idade, sexo. ${ }^{9}$ 
O enfermeiro, ao centrar a sua actuação profissional na relação interpessoal, deveria valorizar e respeitar os valores, crenças e desejos individuais da família, agindo na defesa da autonomia eno respeito pelas opções das pessoas e o seu cuidado. Víamos, assim, respeitado o princípio da dignidade humana como um valor autónomo e específico, inerente aos seres humanos, em virtude da sua personalidade..$^{10}$

O conceito de dignidade é assumido como um princípio moral e como uma disposição do direito positivo. ${ }^{5}$ De tal forma que é um imperativo da enfermagem: "cuidar da pessoa humana sem descriminação económica, social, política, ética, ideológica ou religiosa; abster-se de juízos de valor sobre o comportamento da pessoa assistida e não lhe impor os seus próprios critérios e valores no âmbito da consciência e da filosofia de vida; respeitar e fazer respeitar as opções políticas, culturais, morais e religiosas da pessoa e criar condições para que ela possa exercer, nestas áreas os seus direitos" .5:89 Todos estes imperativos, à luz dos princípios éticos em cuidados de saúde, podem caracterizar a boa prática de enfermagem.

Os princípios éticos são uma referência importante, servindo de linha orientadora na actuação de toda a equipe. Temos o princípio da beneficência, fazer o bem, da não maleficência, primeiramente não fazer o mal, da justiça, distribuição justa, equitativa e apropriada. Inspirado pela imanente dignidade da pessoa reconhecida como um valor a salvaguardar e a promover, o enfermeiro "age na defesa da autonomia e no respeito pelas opções das pessoas ao seu cuidado". 11:146

Existe ainda o princípio da vulnerabilidade, o que evoca a "ferida sangrenta, dolorosa e sofrida". 12:9 É a vulnerabilidade da pessoa perante a doença que faz reclamar por solidariedade e equidade dos prestadores de cuidados considerando, no grupo dos mais vulneráveis, as crianças, os idosos, os deficientes e os doentes inconscientes.

Acabamos de evocar a ferida como fazendo parte do sofrimento, enquanto este aparece ligado ao agir. Todo o agir humano implica uma dimensão do sofrer, toda a acção se constrói sobre condicionantes forçosamente aceites, toda a criação humana surge de um fundo de possibilidade. Agir e sofrer delineiam a estrutura de base da reflexão sobre a vulnerabilidade. ${ }^{12}$

Aqui importa reflectir sobre o significado dos nossos actos e as normas a seguir, se queremos contribuir para a liberdade do outro e, simultaneamente, para a dignidade da pessoa e do técnico que dela cuida. É a ética que qualifica o nosso agir no cuidar, é ela que nos convida a desempenhar o nosso trabalho e não nos determina necessariamente o que devemos fazer. O homem só poderá ser compreendido através da sua experiência. Ele transcende-se através da sua liberdade e do seu compromisso consigo próprio e com os outros. A ética por sua vez acentua a luta do indivíduo contra tudo o que o reprime, abrindo-se a outras perspectivas.

Assim, a ética é um tipo de compreensão humana. O agir, o praticar a acção conduz sempre a um fim, para o bem ou para o mal. A maneira como cada um prevê, como cada um acolhe o acto, bom ou mau, torna-o à partida responsável. É a partir da regulação da sensibilidade que podemos tender para fins regulados, equilibrados e prever o bem. "A referência ao agir significa que o valor deve ser pensado em relação com a acção."13:300

A pessoa realiza-se a si própria, quando pelo seu agir ela instaura três tipos de relações primordiais. Primeiro, a relação consigo mesmo que gera eticamente a estima por si própria. É o reconhecimento de si mesmo como válido. Segundo, aquilo que constitui a pessoa ética é a relação de respeito pelo outro, pela pessoa dos outros. Terceiro viver em instituições justas. A relação com o mundo dos desconhecidos torna-se uma tarefa pessoal. ${ }^{8}$

Na prática do cuidar em enfermagem existem muitas problemáticas relacionadas com o agir ético o que coloca o enfermeiro, por vezes, num domínio puramente reflexivo e o conduz a agir conforme a sua consciência. A consciência é pessoal e intransmissível e, ao agirmos em consciência, agimos com afecto e de acordo com o valor moral dos actos. O acto está na intenção.

"Nós algumas vezes, falamos como se cuidar de alguém, por exemplo, fosse simplesmente uma questão de boas intenções ou atenção calorosa [...] Para cuidar de alguém, tenho que saber muitas coisas. Tenho que saber, por exemplo, quem é o outro, quais os seus poderes e limitações, quais as suas necessidades e o que é que contribui para o seu crescimento; tenho que saber responder às suas necessidades. Tal conhecimento é simultaneamente geral e específico". ${ }^{14: 55}$

Neste agir tão complexo, o ideal e valor do cuidar assume claramente, não apenas qualquer coisa, mas um ponto de partida, um local, uma atitude, que terá de se tornar um desejo, uma intenção, um compromisso e um julgamento consciente que se manifeste em actos concretos. A essência do valor do cuidar assume relevância desde que contribua para uma filosofia de acção, de liberdade humana, escolha e responsabilidade. ${ }^{15}$ 
Os elementos constitutivos de uma verdadeira ética profissional podem ser encontrados em todo o percurso histórico da enfermagem bem como na sua identidade. ${ }^{4}$ Retomando a questão pelo seu outro lado, perguntaremos então se haverá ética no agir em enfermagem, se não houver qualidade nos cuidados que se prestam?

A nossa concordância em relação ao argumento de que uma implica necessariamente a outra parece óbvia, no entanto, faz-nos tomar consciência de que esta qualidade não é dada, em circunstância alguma, antecipadamente nem garantida de modo automático. Encontrar o significado de um cuidar de qualidade, quando esta qualidade se refere à saúde das pessoas, não é tarefa fácil. “O conteúdo do exercício é tão diverso e constituído de inúmeras pequenas coisas, que para cada um assumem uma importãncia ímpar". 15: 37

Neste contexto, "os enfermeiros têm presente que bons cuidados significam coisas diferentes para diferentes pessoas e, assim, o exercício profissional dos enfermeiros requer sensibilidade para lidar com essas diferenças, perseguindo-se os mais elevados níveis de satisfação dos clientes" ${ }^{16: 10}$ De igual forma, eles deverão ter consciência, que a relação que assumem com as pessoas alvo dos seus cuidados assenta no imperativo moral da dignidade ontológica e na preocupação da defesa da sua liberdade.

As acções de enfermagem, quaisquer que elas sejam, não poderão nunca ser amorais. Contudo, a reflexão que se pretende promover vai mais no sentido do empreendimento de um esforço de reflexão axiológica, sendo necessário encontrar modelos explicativos e de análise que permitam, perante o mandato social da profissão que nos comprometemos cumprir, orientar a nossa conduta face às decisões a tomar. É necessário clarificar o que são cuidados de qualidade, o que nos leva a uma abordagem da sua essência e natureza e o que determina, na sua especificidade, a tão desejada qualidade. ${ }^{4}$

A qualidade, conceito tão abstracto, poderá ser descrita como uma filosofia de lutas pela consciência que deve existir a todos os níveis e ser assumida como conceito lato. Claro está, que a qualidade existe sempre em relação a algo mensurável e, neste caso, implica sempre a existência de padrões.

Lançando mão do enorme desafio que se impõe, em Portugal, a Ordem dos Enfermeiros definiu então os padrões de qualidade dos cuidados de enfermagem. Assumiu formalmente, quer por instâncias internacionais, como a Organização Mundial da Saúde e o Conselho Internacional de Enfermagem, quer por organizações nacionais, como o Conselho
Nacional da Qualidade e o Instituto da Qualidade em Saúde, a importância e prioridade na criação do sistema deQualidade em Saúde. Um contributo para garantir esta qualidade pode estar nas seis categorias de enunciados descritivos já definidos: satisfação dos doentes, promoção da saúde, prevenção de complicações, bem-estar e auto cuidado, readaptação funcional e organização dos cuidados de enfermagem.

Em relação à satisfação dos doentes, e na perspectiva da orientação do agir ético em enfermagem, destaca-se, entre outros, o respeito pelas capacidades, crenças, valores e desejo de natureza individual do doente; quanto à promoção da saúde, temos o promover do potencial de saúde do doente através da optimização do trabalho adaptativo ao processo de vida, crescimento e desenvolvimento; face à prevenção de complicações, surge o rigor técnico/científico na implementação das intervenções de enfermagem e a responsabilização do enfermeiro pelas decisões que toma, pelos actos que pratica e que delega. No que se refere ao bem-estar e ao auto cuidado do doente, destaca-se, entre outros, a identificação, mais rapidamente quanto possível, dos problemas do doente, relativamente aos quais o enfermeiro tem conhecimento e está preparado para prescrever, implementar e avaliar as intervenções. A continuidade do processo de prestação de cuidados de enfermagem surge no contexto do desenvolvimento com o doente, de processos de readaptação eficaz aos problemas de saúde. Quanto à organização dos cuidados de enfermagem, destacase a existência de um sistema de melhoria contínua da qualidade do exercício profissional. ${ }^{16}$

E aqui se reforça a dupla perspectiva do processo da melhoria da qualidade: a de saúde ou doença e a do desenvolvimento da enfermagem enquanto profissão e enquanto disciplina.

Torna-se fundamental considerar que a ética no campo da saúde, tem sido objecto de grande atenção por parte da comunidade científico-profissional, o que conduz a uma exigência cada vez mais crescente de cuidados de saúde de qualidade.

\section{SINTETIZANDO...}

Esta reflexão, na qual estão inseridas considerações acerca do agir ético em enfermagem e da qualidade dos cuidados de enfermagem que se prestam, coloca-nos agora face à questão - Como somos capazes de saber o que devemos fazer, em cada momento, na nossa actividade profissional?

Assente nas virtudes do saber, da sabedoria e da prudência podemos sempre seguir o caminho regulado. O saber é a virtude que ajuda na descoberta 
da verdade; a sabedoria é a capacidade de teorização que ajuda a delinear o fim, entendendo este delinear um ponderar, um discernir os prós e os contras dos próprios fins; por último, a prudência, a que os antigos chamavam de sabedoria prática, é a que nos leva a decidir pelos meios para chegar aos fins.

Todo o agir humano tem um objectivo ou um fim, mas isso não significa que este fim seja plenamente consciente. A consciência existe de modo implícito e no decurso da vida humana os actos vão-se inscrevendo em linhas de acção mais amplos, as que determinam a forma de agir da pessoa. ${ }^{17}$

Falar no agir leva a que se fale nas duas virtudes de excelência do comportamento humano, a justiça e a amizade. A justiça inclui a legalidade, a igualdade e a equidade. A amizade, sendo uma virtude máxima, inclui o desejo pelo bem ao outro, a benevolência. "A pessoa é um ser para o qual a única dimensão adequada é o amor. Somos justos com uma pessoa quando a amamos". ${ }^{18: 185}$

Considerar estas virtudes como fundamentais na actividade de enfermagem, é ter em mente que se deve saber aliar o saber científico e técnico, o saber ético e a sabedoria ética prática. O reconhecimento de que se teve a oportunidade de contribuir para que os outros se sentissem melhor, proporciona uma satisfação imensa e promove o sentimento de competência.

É aos enfermeiros, sem dúvida, que cabe a responsabilidade por uma melhoria contínua na realização do seu exercício profissional. "Para que a dignidade da pessoa doente, foco dos cuidados e razão de qualquer intervenção, seja o referencial último e inadiável". ${ }^{11: 147}$

Assegurando, na sua prática, a especificidade da natureza dos cuidados de enfermagem adequados às necessidades reais e potenciais da pessoa ou grupo, suportadas na evidência científica, na ética e deontologia profissional pode garantir-se cuidados de qualidade.

Neste sentido, esta reflexão não tem a pretensão de fornecer respostas mas poderá dar contributos àqueles que estão ao serviço da vida e da saúde das pessoas que neles confiam.

\section{REFERÊNCIAS}

1. Renaud I. Situações do corpo e a ética do cuidado. Cadernos de Bioética. 2004 Dez; 36:5-15.

Correspondência: Maria Goreti Silva Ramos Mendes Universidade do Minho - Escola Superior de Enfermagem Av. Central, 100 , Edifício dos Congregados 4710-229 Braga, Portugal

E-mail:gmendes@ese.uminho.pt
2. Thompson I, Melia K, Boyd K. Ética em Enfermagem. $4^{\mathrm{a}}$ ed. Loures (PT): Lusociência; 2004.

3. Portugal. Decreto-Lei No161/96. Regulamento do Exercício Profissional do Enfermeiro: Diário da República Portuguesa. I Série-A, n. ${ }^{\circ}$ 205. Capítulo II, Art. ${ }^{\circ}$ 4. . . 2959-62.

4. Neves MC, Pacheco S, Queiroz A, Nunes L, Paiva A, Costa MA, et al. Para uma Ética da Enfermagem: Desafios. Coimbra (PT): Gráfica de Coimbra; 2004.

5. Ordem dos Enfermeiros. Código Deontológico do Enfermeiro: Princípios gerais. Lisboa (PT): Ordem dos Enfermeiros; 2005.

6. Portugal. Decreto-Lei No161/96. Regulamento do Exercício Profissional do Enfermeiro: Diário da República Portuguesa. I Série-A, n. ${ }^{\circ}$ 205. Capítulo IV , Art. ${ }^{\circ}$ 8. . . 2959-62.

7. Vieira M. Cuidar defendendo a autonomia da pessoa cuidada. Rev Servir. 1995 Maio-Junho; 43(3):114-7.

8. Renaud I. O corpo enigmático. Cadernos de Bioética. 2004 Abr; 34:33-42.

9. Internacional Council of Nursing. Code for Nurses. Ethical Concepts Applied to Nursing. Geneva (SZ): Internacional Council of Nursing; 1973.

10. Beauchamp TL, Childress JF. Princípios de Ética Biomédica. Barcelona (ES): Masson S.A.; 1999.

11. Vieira M. O enfermeiro. In: Neves MC, Serra A, Pereira, A, Sarmento A, Porto A, Festas C, et al. Comissões de Ética: das bases teóricas à actividade quotidiana. $2^{\mathrm{a}}$ ed. Coimbra (PT): Gráfica de Coimbra; 2002. p. 145-8.

12. Renaud M. Solicitude e vulnerabilidade. Cadernos de Bioética. 1997 Abr; 13:5-9.

13. Renaud M. Os valores num mundo em mutação. Lisboa (PT): Brotéria;1994. p. 299-322.

14. Watson J. Enfermagem. Ciência Humana e Cuidar. Uma teoria de enfermagem. Camarate (PT): Lusociência; 2002.

15. Hesbeen W. Qualidade em Enfermagem: pensamento e acção na perspectiva do cuidar. Loures (PT): Lusociência; 1998.

16. Ordem dos Enfermeiros. Reflexões - Padrões de qualidade dos cuidados de enfermagem. Lisboa (PT): Ordem dos Enfermeiros; 2005.

17. Renaud M. Novas perspectivas sobre a ética e a moral. In: Neves MC, Serra A, Pereira, A, Sarmento A, Porto A, Festas C, et al. Comissões de Ética: das bases teóricas à actividade quotidiana. $2^{\mathrm{a}}$ ed. Coimbra (PT): Gráfica de Coimbra; 2002. p. 15-26.

18. João Paulo II . Atravessar o Limiar da Esperança. Lisboa (PT): Planeta; 1994.

Recebido em: 15 de junho 2008 Aprovação final: 26 de janeiro de 2009 